\title{
KOMPOSISI VEGETASI HUTAN MANGROVE PANTAI AIR MATA PERMAI KECAMATAN MUARA PAWAN KABUPATEN KETAPANG
}

\author{
(Composition of Mangrove Forest Vegetation Air Mata Permai Beach, Muara Pawan \\ Subdistrict Ketapang District)
}

\author{
Zul Padli, Abdurrani Muin, Iskandar \\ Fakultas Kehutanan Universitas Tanjungpura Jalan Daya Nasional Pontianak 78124 \\ Email: zulfadly207@gmail.com
}

\begin{abstract}
The reaserch aimed to obtain data on the composition of mangrove forest vegetation in Air Mata Permai Beach Muara Pawan Subdistrict Ketapang District. The research was carried out on the mangrove forest in Air Mata Permai Beach, Muara Pawan Sub-District, Ketapang Regency in April-May with \pm 1 month implementation time. The research method used in analyzing vegetation in the field is survey the grid line method. Lanes made is 5 (five) with a width of 10 meters and a length of 600 meters which is made perpendicular to the sea to the mainland. The results showed that in the mangrove forest Air Mata Permai Beach there were 16 types of vegetation with compositions consisting of Sonneratia alba, Avicennia alba, Rhizopora apiculata, Bruguiera gymnorrhiza, Exoecaria agallocha, Hibiscus tiliaceus, Lumnitzera littorea, Lumnitzera racemosa, Ceriops decandra, Xylocarpus granatum, Calophyllum inophyllum, Heritiera littoralis, Vitex pinnata, Acrostichum speciosum, Cerbera manghas and Nypa fructians. The dominant type of important value index (INP) is Rhizopora apiculata. The Species Diversity Index $\left(H^{\prime}\right)$ is included in the low category because the value of $H^{\prime}<1$. The $H$ 'value $<1$ indicates that the diversity of species on a transect or forest area is small or low and based on the results of the analysis of the type (e) Abundance Index data as a whole the range is 0,453-0,514, this states that the abundance between species is rather low or the individual wealth of each species is not evenly distributed.
\end{abstract}

Keywords: Composition, Mangrove, Vegetation.

\section{PENDAHULUAN}

Hutan mangrove adalah kelompok jenis tumbuhan yang tumbuh di sepanjang garis pantai tropis sampai sub-tropis. Tipe hutan ini memiliki fungsi penting di suatu lingkungan yang mengandung garam, bentuk lahan berupa pantai dengan reaksi tanah an-aerob (Snedaker, 1978 dalam Petra, et al, 2012). Ciri lain dari tipe hutan ini dimana beberapa jenis pohon mangrove yang mampu tumbuh dan berkembang pada daerah pasang-surut pantai berlumpur (Bengen, 2000 dalam Putro, et al, 2013). Mangrove tumbuh optimal di wilayah pesisir yang memiliki muara sungai besar dan delta yang yang aliran airnya banyak mengandung lumpur. Salah satu tipe hutan mangrove ini terdapat di pantai Air Mata Permai Kecamatan Muara Pawan Kabupaten Ketapang (Putro, et al, 2013).

Hutan Mangrove Pantai Air Mata Permai merupakan kawasan yang telah ditetapkan sebagai kawasan konservasi. Kawasan ini memiliki keanekaragaman jenis flora dan fauna yang bernilai ekonomis tinggi. Pemanfaatan langsung yang dilakukan masyarakat, selama ini untuk memenuhi kebutuhan sehari-hari seperti pengambilan kayu, kepiting dan 
lainnya. Pemanfaatan jenis-jenis mangrove secara langsung berupa kayunya oleh masyarakat, dapat berakibat berubahnya komposisi vegetasi penyusun hutan mangrove. Mengingat kekayaan hayati serta peran dan manfaat lainnya, maka hutan ini harus dipertahankan dan dijaga kelestariannya, melalui pengelolaan dan pembinaan yang tepat berdasarkan komposisi jenis.

Komposisi jenis merupakan data dasar untuk menentukan pengelolaan dan pemanfaatan yang tepat pada hutan mangrove. Informasi data yang menjelaskan komposisi vegetasi Hutan Mangrove Pantai Air Mata Permai sampai saat ini belum ada. Ketiadaan informasi ini, menyebabkan belum maksimalnya pengelolaan dan pembinaan hutan mangrove tersebut. Penelitian bertujuan untuk menentukan komposisi vegetasi hutan mangrove Pantai Air Mata Permai Kecamatan Muara Pawan Kabupaten

1 2
Ketapang. Hasil penelitian diharapkan digunakan sebagai acuan yang akan datang Pantai Air Mata Permai untuk pembinaan dan pengelolaan.

\section{METODOLOGI PENELITIAN}

Penelitian dilaksanakan pada kawasan hutan mangrove Pantai Air Mata Permai Kecamatan Muara Pawan Kabupaten Ketapang pada bulan April-Mei dengan waktu pelaksanaan \pm 1 bulan. Obyek dalam penelitian adalah semua vegetasi mangrove yang ditemukan dalam petak pengamatan, berupa tingkat semai, pancang dan pohon. Penelitian dilakukan dengan metode survei garis berpetak. Jalur dibuat sebanyak 5 (lima) buah selebar 10 meter dan panjang 600 meter dengan arah tegak lurus dari arah laut menuju daratan. Peletakan jalur pertama di lakukan secara purposive dan peletakan jalur berikutnya berjarak 100 meter dari jalur lainnya. Pola jalur dan petak pengamatan disajikan pada gambar 1.

Dst

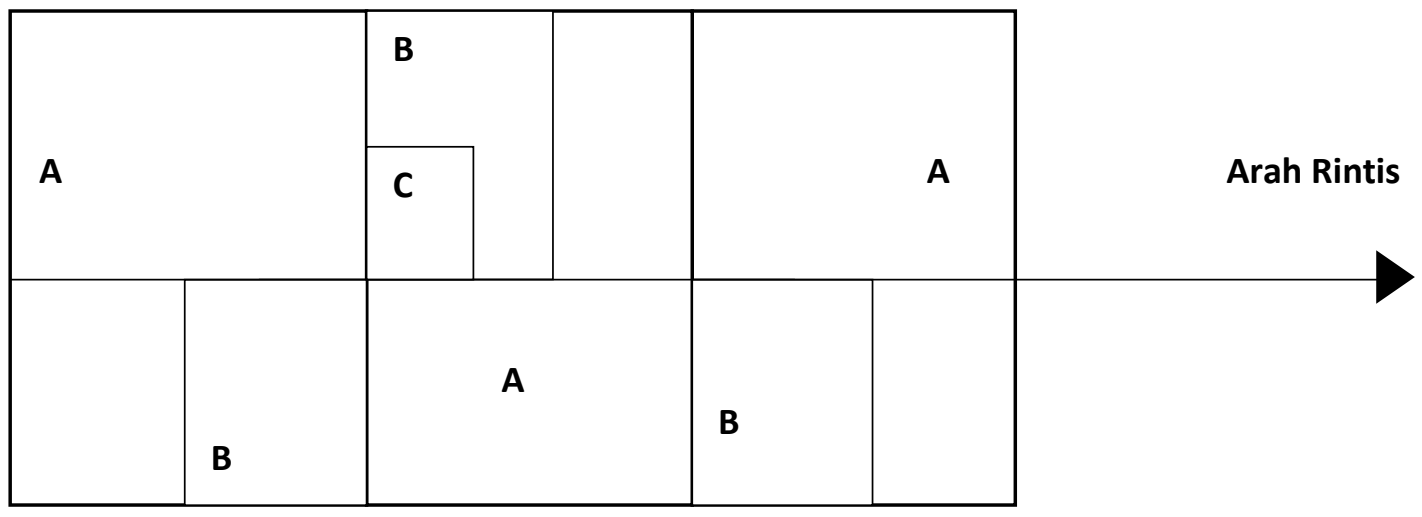

Gambar 1. Desain Petak Contoh Penelitian Komposisi Hutan Mangrove Pantai Air Mata Permai (Grid Design Examples of Research on the Composition of Mangrove Forests Air Mata Permai Beach)

Keterangan :

Petak $\mathrm{A}=$ petak $10 \mathrm{~m} \times 10 \mathrm{~m}$ untuk pengamatan pohon (tree)

Petak $\mathrm{B}=$ petak $5 \mathrm{~m} \times 5 \mathrm{~m}$ untuk pengamatan pancang (sapling)

Petak $\mathrm{C}=$ petak $2 \mathrm{~m} \times 2 \mathrm{~m}$ untuk pengamatan semai (seedling). 
Data yang dikumpulkan terdiri dari tingkat semai (tinggi 1,5 meter atau kurang), tingkat pancang (diameter $<10$ $\mathrm{cm}$ dan tingginya lebih dari 1,5 meter) dan pohon (berdiameter $>10 \mathrm{~cm}$ ). Data yang diperoleh dari hasil pengukuran di lapangan dianalisis dengan menggunakan rumus sebagai berikut.

\subsection{Indeks Nilai Penting (INP) (\%):}

1. Tingkat pohon dan pancang adalah INP $=\mathrm{KR}+\mathrm{FR}+\mathrm{DR}$

2. Tingkat semai adalah $\mathrm{INP}=$ $\mathrm{KR}+\mathrm{FR}$
a. Kerapatan
(K)
$=$

Jumlah individu suatu jenis

Luas petak pengamatan

b. Kerapatan relative

(KR)

$=\frac{\text { Kerapatan suatu jenis }}{\text { Kerapatan seluruh jenis }} \times 100 \%$

c. Frekuensi (F) =

Jumlah petak penemuan suatu jenis Jumlah seluruh petak

d. Frkuensi Relative (FR)

$=\frac{\text { Frekuensi suatu jenis }}{\text { Frekuensi }} \times 100 \%$

e. Dominasi (D) =

Luas bidang dasar suatu jenis Jumlah petak ukur

f. Dominasi Relative (DR) = $\frac{\text { Dominasi suatu jenis }}{\text { Dominasi seluruh jenis }} \times 100 \%$

\subsection{Indeks Dominasi (C)}

Menurut Fachrul (2006), Indeks Dominasi (C) digunakan untuk menentuukan dominasi dalam suatu komunitas menggunakan rumus pemusatan dominasi sebagai berikut :

$\mathrm{C}=\sum \frac{n i(n i-1)}{N(N-1)}$

Dimana :

$\mathrm{C}=$ Indeks Dominasi

$\mathrm{Ni}=$ Jumlah individu dari jenis $\mathrm{ke}-\mathrm{i}$

$\mathrm{N}$ = Jumlah Individu dari semua jenis

\subsection{Indeks Keanekaragaman Jenis}

(H')

Indeks keanekaragaman jenis (H') digunakan untuk mengetahui keanekaragaman jenis dari tegakan hutan. Rumus yang digunakan menurut Shannon-wiener (Odum, 1993) sebagai berikut :

$\mathrm{H}^{\prime}=\sum \frac{n i}{N} \log \frac{n i}{N}$

Dimana :

$\mathrm{H}^{\prime} \quad=$ Indeks keanekaragaman jenis

ni $=$ Nilai penting jenis ke -1

$\mathrm{N}=$ Total nilai penting

$\mathrm{H}^{\prime}<1=$ Keanekaragaman rendah

$1<\mathrm{H}^{\prime}<3=$ Keanekaragaman sedang

$\mathrm{H}^{\prime}>3=$ Keanekaragaman tinggi

\subsection{Indeks Kelimpahan Jenis (e)}

Indeks kelimpahan jenis dipengaruhi oleh keanekaragaman jenis dan jumlah jenis digunakan untuk mengetahui kelimpahan suatu jenis area atau pada suatu ukuran contoh tertentu, maka dipergunakan rumus indeks evennes (Odum, 1993) :

$\mathrm{e}=\frac{H^{\prime}}{\log S}$

Dimana :

e $\quad=$ Indeks kemerataan jenis

$\mathrm{H} \quad=$ Indeks keanekaragaman jenis

$\mathrm{S} \quad=$ Jumlah jenis

\section{HASIL DAN PEMBAHASAN}

Komposisi jenis merupakan penyusun suatu tegakan atau hutan yang meliputi jumlah jenis ataupun banyaknya individu dari suatu jenis tumbuhan. Berdasarkan hasil analisa 
vegetasi yang dilakukan pada hutan mangrove Pantai Air Mata Permai, komposisi jenis vegetasi dari seluruh tingkat pertumbuhan terdapat 16 jenis dari 13 famili. Selanjutnya, dari keseluruhan vegetasi tingkat semai terdapat 9 jenis dari 8 famili, tingkat pancang ditemukan 13 jenis dari 10 famili dan tingkat pohon 10 jenis dari 9 famili. Berdasarkan hasil analisa vegetasi yang dilakukan di lapangan, pada setiap jalur ditemukan komposisi jenis yang berbeda-beda (Tabel 1).

Tabel 1. Jenis-Jenis yang Ditemukan dalam Petak Pengamatan (Types Found in Observation Plots)

\begin{tabular}{|c|c|c|c|}
\hline No & Nama Ilmiah & Nama Lokal & Family \\
\hline 1 & Sonneratia alba & Perepat & Sonneratiaceae \\
\hline 2 & Rhizopora apiculata & Bakau & Rhizoporaceae \\
\hline 3 & Avicennia alba & Api-api & Avicenniaceae \\
\hline 4 & Exoecaria agallocha & Bebutak & Euphorbiaceae \\
\hline 5 & Hibiscus tiliaceus & Baruk Laut & Malvaceae \\
\hline 6 & Vitex pinnata & Leban & Verbenaceae \\
\hline 7 & Lumnitzera racemosa & Teruntum & Combretaceae \\
\hline 8 & Bruguiera gymnorrhiza & Tumuk & Rhizoporaceae \\
\hline 9 & Acrostichum speciosum & Pakuk laut & Pteridaceae \\
\hline 10 & Ceriops decandra & Tengar & Rhizoporaceae \\
\hline 11 & Lumnitzera littorea & Teruntum Merah & Combretaceae \\
\hline 12 & Heritiera littoralis & Dungun & Sterculiaceae \\
\hline 13 & Nypa fructians & Nipah & Arecaceae \\
\hline 14 & Calophyllum inophyllum & Penage & Clusiaceae \\
\hline 15 & Cerbera manghas & Mentaro & Apocynaceae \\
\hline 16 & Xylocarpus granatum & Nyireh & Meliaceae \\
\hline
\end{tabular}

Berdasarkan Tabel diatas komposisi jenis vegetasi dari seluruh tingkat pertumbuhan terdapat 16 jenis dari 13 famili. Avicennia alba bisa ditemukan 0-120 meter dari tepi laut. Menunjukan bahwa Avicennia alba bisa ditemukan di sepanjang garis pantai maupun di pantai yang terlindung. Hal ini sesuai dengan Noor, Khazali dan Suryadiputra (2006) yang mengatakan bahwa Avicennia alba merupakan jenis pionir pada habitat rawa mangrove di lokasi pantai yang terlindung. Sonneratia alba hanya bisa ditemukan pada 0-60 meter dari tepi laut atau hanya pada zona yang berhadapan langsung dengan laut saja. Berdasarkan penelitian Madiana, et al, (2016) zonasi hutan mangrove di daerah Negeri Passo di dominasi jenis Sonneratia alba pada zonasi luar atau zona yang berhadapan dengan laut. Tumbuhan ini merupakan salah satu jenis tumbuhan mangrove yang banyak tumbuh di daerah tropis.

Lumnitzera littorea di temukan pada jarak 61-120 meter darai tepi laut karena di jarak tersebut adanya laguna. Lumnitzera littorea adalah salah satu jenis mangrove sejati yang sudah jarang ditemui karena keberadaannya semakin menyusut. Hal ini disebabkan karena habitatnya yang banyak dimanfaatkan untuk pembangunan wilayah 
pesisir. Pantai Air Mata Permai pada jarak 60-120 terdapat laguna sehingga tumbuhnya mangrove seperti Cerbera manghas, Vitex pinnata, Nypa fructians, Calophyllum inophyllum, Hibiscus tiliaceus dan Heritiera littoralis. Menurut Sukardjo (1985) pada masa kini pola zonasi tidak jelas karena adanya sedimentasi dan perubahan habitat. Hal ini di dukung oleh Setyawan, et al, (2005) mengatakan bahwa muara-muara sungai membentuk laguna karena adanya gosong pasir di mulut muara. Hal ini terjadi karena aliran air sungai yang mengandung sedimen tanah dari daratan menuju laut bertemu dengan gelombang laut menuju daratan yang membawa butiran-butiran pasir.

Lumnitzera racemosa bisa ditemukan pada jarak 0-60 dan 121-180 meter dari tepi laut karena pada jarak tersebut wilayahnya berupa pasir/lumpur atau gabungan keduanya dan juga tidak jauh dari sungai sehingga bisa ditumbuhi jenis Lumnitzera racemosa. Xylocarpus granatum ditemukan pada beberapa lokasi yang tidak menentu karena Xylocarpus granatum bisa tumbuh sepanjang pinggiran sungai pasang surut dan lingkungan payau yang tidak terlalu asin. Hal ini didukung penelitian Noor, Khazali dan Suryadiputra (2006) mengatakan bahwa Xylocarpus granatum tumbuh di sepanjang pinggiran sungai pasang surut, pinggir daratan dari mangrove dan lingkungan payau lainnya yang tidak terlalu asin. Acrostichum speciosum pada penelitian ini tidak ditemukan pada zona depan atau zona yang yang berhadapan langsung dengan laut melainkan ditemukan pada daerah yang terlindung atau pada gundukaan lumpur. Exoecaria agallocha hampir di temukan pada setiap lokasi terutama yang tidak begitu jauh dari sungai karena menurut Rusila, Khazali dan Suryadiputra (2006) bahwa tumbuhan ini perbungaannya terjadi sepanjang tahun dan sepanjang tahun memerlukan masukan air tawar dalam jumlah besar. Umumnya ditemukan pada bagian pinggir mangrove di bagian daratan, atau kadang-kadang di atas batas air pasang.

Bruguiera gymnorrhiza merupakan jenis yang ditemukan pada seluruh lokasi pengamatan yaitu sepanjang $600 \mathrm{~m}$ dari tepi laut. Menurut Noor, Khazali dan Suryadiputra (2006) Bruguiera gymnorrhiza dapat tumbuh di areal dengan salinitas rendah dan kering, serta tanah yang memiliki aerasi yang baik. Jenis ini toleran terhadap daerah terlindung maupun yang mendapat sinar matahari langsung. Jenis yang mendominasi pada ke-5 jalur dan ditemukan sepanjang 600 meter dari arah laut kedaratan adalah Rhizopora apiculata. Hal ini didukung oleh (Silaen,et al, 2013) yang mengatakan bahwa pada hutan mangrove di Teluk Awur Jepara dimana Rhizopora apiculata mendominasi pada semua tingkatan pertumbuhan, karena kemampuan jenis ini beradaptasi dengan faktor-faktor lingkungan lebih baik bila dibandingkan dengan jenis lain. Noor, Khazali dan Suryadiputra (2006) juga mengatakan bahwa jenis-jenis vegetasi yang mampu menguasai suatu areal adalah jenis-jenis yang mampu beradaptasi terhadap lingkungannya, sehingga dapat berkembang dan tumbuh dengan baik. Variasi atau keanekaragam jenis penyusun hutan mangrove yang lebih kecil dibandingkan dengan variasi jenis untuk formasi hutan alam lainnya. Hal ini dipengaruhi oleh adanya 
perbedaan kualitas tempat tumbuh yaitu salinitas, ph, hantaman angin serta air laut, kondisi tekstur dan topografi.

\subsection{Indeks Nilai Penting Tingkat Semai, Pancang dan Pohon}

Berdasarkan hasil analisa vegetasi menunjukan bahwa jenis-jenis yang mendominasi pada kawasan hutan mangrove Pantai Air Mata Permai untuk tingkat semai adalah jenis Rhizopora apiculata 95,868\%, Bruguiera gymnorrhiza (75,340\%) dan Acrostichum speciosum (22,695\%). Hasil analisa vegetasi untuk INP yang terkecil pada tingkat semai dengan rerata terkecil adalah Avicennia alba (1,676\%), Exoecaria agallocha (1,631\%), Hibiscus tiliaceus (1,230\%), Nypa fructians (0,757\%), Heritiera littoralis $(0,401 \%)$ dan Cerbera manghas $(0,401 \%)$. (Tabel 2$)$.

Tabel 2. Rekapilutasi Indeks Nilai Penting (INP) pada Tingkat Semai, Pancang dan Pohon (Recapilutation of Important Value Index (INP) at Seedling, Stake and Tree Levels)

\begin{tabular}{clccc}
\hline \multirow{2}{*}{ No } & \multicolumn{1}{c}{ Nama Jenis } & \multicolumn{3}{c}{ INP/Tingkat Pertumbuhan $(\%)$} \\
\cline { 3 - 5 } & & Semai & Pancang & Pohon \\
\hline 1 & Sonneratia alba & - & 2,348 & 6,418 \\
2 & Rhizopora apiculata & 95,868 & 137,974 & 133,779 \\
3 & Avicennia alba & 1,676 & 1,998 & 5,662 \\
4 & Exoecaria agallocha & 1,631 & 11,254 & 19,288 \\
5 & Hibiscus tiliaceus & 1,230 & 8,619 & 2,593 \\
6 & Vitex pinnata & - & 1,862 & 1,446 \\
7 & Lumnitzera racemosa & - & 0,978 & - \\
8 & Bruguiera gymnorrhiza & 75,340 & 129,877 & 127,617 \\
9 & Acrostichum speciosum & 22,695 & - & - \\
10 & Ceriops decandra & - & 1,135 & - \\
11 & Lumnitzera littorea & - & 0,780 & 0,735 \\
12 & Heritiera littoralis & 0,401 & 0,868 & 1,175 \\
13 & Nypa fructians & 0,757 & - & - \\
14 & Calophyllum inophyllum & - & 0,481 & - \\
15 & Cerbera manghas & 0,401 & - & - \\
16 & Xylocarpus granatum & - & 1,825 & 1,287 \\
\hline
\end{tabular}

Hasil pengolahan data Indeks Nilai Penting untuk tingkat semai menunjukkan bahwa jenis Rhizophora apiculata adalah yang paling tinggi. Hal ini menunjukkan bahwa untuk tingkat semai tingkat penguasaan jenis Rhizophora apiculata adalah yang paling tinggi dibandingkan jenis-jenis yang lain. Menurut Kusmana, et al, (2003) hal ini diduga karena faktor tempat tumbuh yang memang cocok untuk jenis Rhizophora apiculata yang pada umumnya ditanah berlempung dan berhumus dengan aerasi yang baik.

Berdasarkan hasil analisa vegetasi pada Tabel 2 bahwa jenis-jenis yang mendominasi pada kawasan hutan mangrove Pantai Air Mata Permai untuk tingkat pancang adalah jenis Rhizopora apiculata $(137,974 \%)$ dan Bruguiera gymnorrhiza $(129,877 \%)$. Hasil analisa vegetasi untuk INP yang terkecil pada tingkat pancang dengan rerata terkecil adalah jenis Exoecaria agallocha $(11,254 \%)$, Hibiscus tiliaceus 
(8,619\%), Sonneratia alba (2,348\%), Avicennia alba (1,998\%), Vitex pinnata (1,862\%), Xylocarpus granatum (1,825\%), Ceriops decandra (1,135\%), Lumnitzera racemosa $(0,978 \%)$, Heritiera littoralis $(0,868 \%)$, Lumnitzera littorea $(0,780 \%)$ dan Calophyllum inophyllum 0,481\%, (Tabel 2). Brugueira gymnorrhiza memiliki nilai $(129,877 \%)$ dan Rhizophora apiculata $(137,974 \%)$ merupakan Indeks Nilai Penting tertinggi artinya bahwa pada tingkat pancang kedua jenis ini sering kali di jumpai pada plot. Kondisi ini berarti bahwa pada tingkat pancang hanya didominasi oleh dua jenis, sehingga dapat dikatakan bahwa pada wilayah ini keragaman jenis rendah namun tingkat dominansi tinggi (Tabba, Wahyuni dan Mokodompit, 2015).

Hasil menunjukan jenis yang mendominasi untuk tingkat pohon di hutan mangrove Pantai Air Mata Permai adalah Rhizopora apiculata (133,779\%), Bruguiera gymnorrhiza $(127,617 \%)$ dan Exoecaria agallocha $(19,288 \%)$. Hasil analisa vegetasi untuk INP yang terkecil pada tingkat pohon dengan rerata terkecil adalah jenis Sonneratia alba (6,418\%), Avicennia alba (5,662\%), Hibiscus tiliaceus (2,593\%), Vitex pinnata (1,446\%), Xylocarpus granatum (1,287\%), Heritiera littoralis $(1,175 \%)$ dan Lumnitzera littorea $(0,735 \%)$. Vegetasi tingkat pohon menggambarkan kompetisi dalam hal penguasaan terhadap areal tempat tumbuh oleh jenis-jenis mangrove. Rhizophora apiculata memiliki kerapatan paling tinggi. Hal ini sangat dimungkinkan sebab jenis ini ditunjang dengan sistem perakaran yang menguasai areal tempat tumbuh yang cukup luas. Sehingga kerapatan dari suatu tegakan merupakan representasi dari jumlah tumbuhan yang tersebar dan menguasai luasan tertentu. Kerapatan menunjukkan pola penyesuaian suatu jenis dengan lingkungannya, jenis dengan nilai kerapatan tinggi memiliki pola penyesuaian yang besar (Fachrul, 2007).

Brugueira gymnorrhiza memiliki Indeks Nilai Penting $(127,617 \%)$ dan Rhizophora apiculata $(133,779 \%)$ artinya bahwa pada tingkat pohon kedua jenis ini sering kali dijumpai pada plot. Kondisi ini berarti bahwa pada tingkat pohon hanya didominasi oleh dua jenis, sehingga dapat dikatakan bahwa pada hutan Mangrove Pantai Air Mata Permai keragaman jenis rendah namun tingkat dominansi tinggi. Menurut Indriyanto (2010) bahwa suatu komunitas dikatakan memiliki keanekaragaman spesies yang rendah jika komunitas itu disusun oleh sedikit spesies dan hanya sedikit saja spesies yang dominan. Sedangkan Indeks Dominansi adalah parameter yang menyatakan tingkat terpusatnya penguasaan spesies dalam suatu komunitas dimana terpusat pada satu spesies, beberapa spesies, atau pada banyak spesies.

Berdasarkan data yang ada dapat disimpulkan bahwa jenis yang dominan pada semua tingkat pertumbuhan (semai, pancang, pohon) adalah jenis Rhizopora apiculata dengan Indeks Nilai Penting (INP) berturut-turut 95,868\%, 137,974\% dan 133,779\%. Setyawan, et al, (2005) mengatakan bahwa spesies mangrove memiliki tingkat adaptabilitas yang tinggi terutama pada jenis tertentu seperti propagul pada jenis Rhizophora sp umumnya telah tumbuh sejak masih menempel pada batang induknya (vivipar) sehingga tingkat keberhasilan pertumbuhan menjadi lebih besar. Hal ini sesuai 
dengan yang dinyatakan Noor, Khazali dan Suryadiputra (2006) bahwa tingkat dominasi Rhizopora apiculata dapat mencapai $90 \%$ dari vegetasi yang tumbuh di suatu lokasi dan merupakan ciri-ciri perkembangan tahap akhir dari hutan pantai serta tahap awal dalam transisi menjadi hutan daratan..

\subsection{Indeks Dominasi $(C)$}

Berdasarkan hasil pengamatan pada hutan mangrove Pantai Air Mata Permai yang telah di analisa menunjukan Nilai Indeks Dominasi (C) dari suatu jenis tegakan adalah kurang $(<$ ) dari 1 (satu) yang ditunjukan dengan nilai $\mathrm{C}=0$, yaitu tingkat semai 0,364 , tingkat pancang 0,425 dan tingkat pohon 0,364 (Tabel 5).

Tabel 3. Rekapilutasi Indeks Dominasi (C) (Recapitulation of Dominance Index $(C)$ )

\begin{tabular}{clll}
\hline No & & Tingkat Vegetasi & Hasil \\
\hline 1 & Semai & 0,388 \\
2 & Pancang & 0,425 \\
3 & Pohon & 0,364 \\
\hline
\end{tabular}

Keterangan: nilai $\mathrm{C}$ dalam kisaran 0,364-0,425.

Indeks Dominasi (C) digunakan untuk menentukan tingkat dominasi atau pemusatan suatu jenis dalam kawasan hutan. Nilai Indeks Dominasi (C) tertinggi adalah 1 (satu) artinya dominasi lebih terkonsentra si pada satu jenis dan sebaliknya jika beberapa jenis mendominasi secara bersama-sama maka nilai indeks dominasi akan rendah. Berdasarkan data diatas hasil analisa data kuantitatif untuk semua tingkat pertumbuhan adalah Nilai Indeks Dominasi (C) dalam kisaran 0,364-0,425 atau $\mathrm{C}<1$ menunjukan bahwa tingkat dominasi pada hutan mangrove Pantai Air Mata Permai tidak terpusat pada satu jenis tetapi terpusat pada beberapa jenis vegetasi. Hal ini Tabel 4. Rekapilutasi Indeks Keanekaragaman Jenis (H') (Recapilutation of the Species Diversity Index $\left.\left(H^{\prime}\right)\right)$

\begin{tabular}{clc}
\hline No & Tingkat Vegetasi & Hasil \\
\hline 1 & Semai & 0,488 \\
2 & Pancang & 0,504 \\
3 & Pohon & 0,514 \\
\hline
\end{tabular}

Keterangan: nilai D dalam kisaran 0,488-0,514. dikarenakan vegetasi mangrove kerap membentuk zonasi-zonasi yang sesuai dengan faktor tumbuh, misalnya zona terdepan terjadi pemusatan pada Avicennia alba, kemudian semakin ke arah darat zona Rhizophora apiculata.

\subsection{Indeks Keanekaragaman Jenis (H)}

Menurut Indriyanto (2006), keanekaragaman jenis suatu komunitas tinggi jika komunitas itu disusun oleh banyak jenis, sebaliknya suatu komunitas dikatakan rendah apabila memiliki keanekaragaman jenis yang rendah jika komunitas itu disusun oleh sedikit jenis dan hanya sedikit jenis yang dominan. 
Keanekaragaman jenis di hutan mangrove Pantai Air Mata Permai untuk tingkat pohon memiliki nilai 0,514 , tingkat pancang 0,504 dan tingkat semai 0,488. Ketiga tingkatan pertumbuhan ini memiliki nilai keanekaragaman yang relatif rendah, dikarenakan nilai indeks keanekaragamnan jenis pada semua tingkat pertumbuhan memiliki nilai $\mathrm{H}<1$. Nilai $\mathrm{H}<1$ menunjukan bahwa keanekaragaman jenis pada suatu transek atau kawasan hutan adalah sedikit atau rendah (Fachrul, 2006). Dibandingkan dengan nilai indeks keanekaragaman jenis menurut kriteria klasifikasi ShannonWieners (1949) dalam Ludwig dan Reynolds (1988), termasuk dalam kategori rendah. Berdasarkan klasifikasi nilai indeks keanekaragaman menurut Shannon-Wienner tersebut, maka dapat dikatakan bahwa pada fase semai, pancang Tabel 5. Rekapilutasi Indeks Kelimpahan Jenis (e) (Recapilutation Type Abundance

\begin{tabular}{clc}
\multicolumn{2}{c}{ Index $(e))$} & \\
\hline No & Tingkat Vegetasi & Hasil \\
\hline 1 & Semai & 0,511 \\
2 & Pancang & 0,453 \\
3 & Pohon & 0,514 \\
\hline
\end{tabular}

Keterangan: nilai e dalam kisaran 0,453-0,514.

Berdasarkan hasil analisa vegetasi secara kuantitatif untuk semua tingkat pertumbuhan menunjukan nilai kelimpahan (e) dalam kisaran 0,453-0,514. Nilai ini menyatakan kawasan hutan mangrove Pantai Air Mata Permai memiliki kelimpahan antar spesies agak rendah artinya kekayaan individu yang dimiliki masing-masing spesies kurang merata. Menurut Michael (1995) kelimpahan setiap spesies individu biasanya dinyatakan sebagai suatu persen jumlah total spesises yang ada dalam maupun pohon tergolong rendah. Kondisi kestabilan ekosistem serta proses suksesi yang terjadi pada semua tingkat pertumbuhan juga dalam kondisi rendah. Keanekaragaman jenis yang rendah pada hutan mangrove Pantai Air Mata Permai dikarenakan adanya variasi lingkungan yang dimana perubahan faktor lingkungan (salinitas) akan menyebabkan perbedaan komposisi suatu jenis (Soerianegara dan Indrawan, 1988).

\subsection{Indeks Kelimpahan Jenis (e)}

Indeks Kelimpahan Jenis (e) merupakan salah satu bagian dari komponen keanekaragaman jenis seperti yang dikemukan oleh Odum (1996), bahwa keanekaragaman jenis itu mempunyai sejumlah komponen yang dapat memberikan reaksi secara berbedabeda terhadap faktor-faktor geografi dan perkembangan fisik.

komunitas dan dengan demikian merupakan pengukuran yang relatif. Nilai relatif ini, akan diperoleh sebuah nilai yang merupakan INP. Secara bersama-sama, kelimpahan dan frekuensi adalah sangat penting dalam menentukan struktur komunitas.

\section{KESIMPULAN DAN SARAN}

Hasil penelitian menunjukan bahwa di kawasan hutan mangrove Pantai Air Mata Permai terdapat 16 jenis vegetasi dengan komposisi terdiri dari Sonneratia alba, Avicennia alba, Rhizopora apiculata, 
Bruguiera gymnorrhiza, Exoecaria agallocha, Hibiscus tiliaceus, Lumnitzera littorea, Lumnitzera racemosa, Ceriops decandra, Xylocarpus granatum, Calophyllum inophyllum, Heritiera littoralis, Vitex pinnata, Acrostichum speciosum, Cerbera manghas dan Nypa fructians. Berdasarkan hasil analisa data pada hutan mangrove Pantai Air Mata Permai, jenis yang memiliki Indeks Nilai Penting (INP) tertinggi pada tingkat pohon, pancang dan semai adalah Rhizopora apiculata. Indeks Dominasi (C) menunjukan tidak ada pemusatan atau penguasaan jenis. Berdasarkan Indeks Keanekaragaman Jenis (H') termasuk dalam kategori rendah karena nilai $\mathrm{H}^{\prime}<1$ dan berdasarkan hasil analisa data Indeks Kelimpahan Jenis (e) secara menyeluruh kisaran 0,453-0,514. Nilai ini menyatakan bahwa penyebaran tiap jenis individu pada hutan mangrove Pantai Air Mata Permai kurang merata. Perlu dilakukan penelitian lanjutan dengan mengkaji faktor-faktor lingkungan yang berpengaruh terhadap komposisi vegetasi penyusun hutan mangrove Pantai Air Mata Permai sehingga diperoleh informasi ilmiah yang lebih kompleks.

\section{DAFTAR PUSTAKA}

Fachrul FM. 2006. Metode Sampling Bioekologi. Bumi Aksara. Jakarta.

Fachrul FM. 2007. Metode Sampling Bioekologi. (cetakan pertama). Sinar Grafika Offset.Jakarta.

Indriyanto. 2006. Ekologi Hutan. Dicetak oleh Sinar Grafika Offset. Diterbitkan PT. Bumi Aksara. Jakarta.Indriyanto. 2010. Ekologi Hutan. Cetakan Ketiga. Dicetak oleh Sinar Grafika Offset.
Diterbitkan PT. Bumi Aksara. Jakarta.

Kusmana C, Wilarso S, Hilwan I, Pamungkas, Wibowo C, Tiryana T, Triswanto A, Yusnawi dan Hamzah. 2003. Teknik Rehabilitasi Mangrove. Fukultas Kehutanan Institut Pertanian Bogor. Bogor.

Ludwig JA and Reynolds JF. 1988. Statistical Ecology. New York: John Wiley and Sons.

Madiana S, Muryani C dan Santoso S. 2016. Kajian Perubahan Luas dan Pemanfaatan Serta Persepsi Masyarakat Terhadap Pelestarian Hutan Mangrove di Kecamatan Teluk Ambon Baguala. Jurnal GeoEco. 2(2), pp.170-183.

Michael P. (1995). Metode ekologi untuk penyelidikan ladang dan laboratorium. Jakarta: Universitas Indonesia Press.

Noor YR, Khazali M dan Suryadiputra INN. 2006. Panduan Pengenalan Mangrove di Indonesia. PHKA/WHP, Bogor.

Odum EP. 1996. Dasar-Dasar Ekologi. Terjemahan dari Tjahojono Samingan, Edisi Ketiga Gajah Mada oleh Universitas Press, Yogyakarta

Petra JL, Sastrawibawa S dan Riyantim I. 2012. Pengaruh Kerapatan Mangrove Terhadap Laju Sedimen Fransper di Pantai Karangsong Kabupaten Indramayu. Fakultas Perikanan dan Ilmu Kelautan UNPAD. Jawa Tengah.

Putro ES, Tasirin JS, Lasut MT dan Langi MA. 2013. Struktur dan Komposisi Vegetasi Mangrove di Pulau Mantehage. Universitas Sam Ratulangi. Manado. 
Setyawan AD, Indrowuryatno, Wiryanto, Winarno K dan Susilosati A. 2005. Tumbuhan Mangrove di Pesisir Jawa Tengah : 1. Keanekaragaman Jenis Biodiversitas. Vol 6 Nomor 2 : 90-94

Silaen IF, Hendrarto B dan Supardjo MN. 2013. Distribusi dan Kelimpahan Gastropoda Pada Hutan Mangrove Teluk Awur Jepara. Journal of Management of Aquatic Resources. Volume 2, Nomor 3, Tahun 2013, Halaman 93-103. Jurusan
Perikanan, Fakultas Perikanan dan Ilmu Kelautan, Universitas Diponegoro.

Soerinegara I dan Indrawan A. 1988. Ekologi Hutan Indonesia. Fakultas Kehutanan. IPB. Bogor.

Tabba S, Wahyuni IN dan Mokodompit HS. 2015. Komposisi dan Struktur Vegetasi Mangrove Tiwoho di Kawasan Taman Nasional Bunaken. Balai Penelitian Kehutanan Manado. Sulawesi Utara. 